\title{
INVESTIGATION OF AN AIRCRAFT ACCIDENT BY FRACTOGRAPHIC ANALYSIS
}

\author{
R. V. Krishnan, S. Radhakrishnan, A. C. Raghuram and V. \\ Ramachandran
}

Materials Science Division, National Aeronautical Laboratory, Bangalore 560017, India

ABSTRACT

A Boeing 737 passenger aircraft suffered a mid-air explosion. in the front toilet area during a scheduled flight and forced the pilot to make an emergency landing. In that process the aircraft overshot the runway damaging its undercarriage and underside. To determine the primary cause of explosion and its exact location, extensive fractographic examination was carried out on the fragments found near the explosion area. These fragments contained signatures characteristic of explosive fracture. The exact location of these fragments in the original aircraft structure was identified. It was concluded that the accident was due to a chemical explosion inside the front toilet of the aircraft. By tracing the trajectories of the projectiles flying in various directions following the explosion, the centre of the explosion, i.e., the location of the explosive device in the aircraft was established to be the waste paper receptacle placed under the wash basin.

\section{KEYWORDS}

Aircraft accident; explosive fracture; signatures; fractography; trajectory tracing.

\section{INTRODUCTION}

A Boeing 737 aircraft on a scheduled domestic flight from Trivandrum, India, suffered a mid-air explosion near the front toilet area, approximately 20 minutes before landing at Madras airport. Due to the explosion, the instruments were not available to the pilot and he had to resort to emergency landing. In that process the aircraft overshot the runway causing severe damage to its undercarriage and underside. To determine the nature and cause of explosion which was primarily responsible for the accident, extensive examination of the debris and chemical examination of the residue deposits were carried out. This paper describes the detailed fracture investigation of 
the fragments and also the trajectory tracing to locate the centre of explosion.

\section{EXAMINATION OF WRECKAGE}

The general view of the damaged aircraft is shown in Fig. 1. The engines and the landing gear got ripped off and the aircraft was resting on its belly near the outer fence of the airport. Extensive damage was noticed in the front toilet and the cockpit areas. Fragments were found lodged at various locations such as the pilot's seat, the observer's seat behind the pilot's seat in the cockpit, toilet panels and the panel opposite the toilet across the gangway.

The three panels of the toilet compartment - one on the cockpit side, another on the gangway side and the third on the cabin side - had given way. There were indications of sharp projectiles passing through them. The floor board of the toilet below the wash basin had been destroyed. The paint on the external skin above the front toilet had peeled off at a few places as seen in Fig.1. On the external skin of the toilet roof, a hole was found, with its edges curling outwards as shown in Fig.2. Inside the toilet, the stainless steel wash basin was found severely deformed. The bulkhead, the side panel and the fittings below the wash basin were severely damaged. The glass mirror above the wash basin was found shattered and the pieces were found in the cockpit and also on the ground below.

The waste towel receptacle which is an aluminium box kept under the wash basin was found disintegrated into a number of heavily deformed pieces. The toilet bowl located to the left of the waste towel cupboard was found caved in as shown in Fig.3, as though deformed by forces from the direction of the waste towel cupboard.

In the cockpit, the glass covers on many of the instruments were found broken as shown in Fig.4. A hole was found on the back rest of the observer's seat which is located between the pilot's seat and the toilet wall. The back rest of the pilot's seat had a hole pierced through it and was damaged as seen in Fig.5.

In the passenger cabin, the quadrant shaped translucent plastic panel located in front of the left front row of seats had a hole pierced through it as shown in Fig.6. The cabin crew's folding seat located in the passage between this panel and the front toilet was completely ripped off into small pieces and sharp metal pieces were found embedded in the foam.

A large number of small metal fragments were recovered from the front toilet and cockpit areas and from the ground below for further examination.

\section{FRACTOGRAPHIC EXAMINATION}

The pieces thus recovered were found severely deformed, curled and twisted. Some of them contained sharp dents and holes pierced through them. On the edges of these holes, the metal lips had curled outwards. Distinct curling was also noticed along the fracture edges of several other metal pieces. 


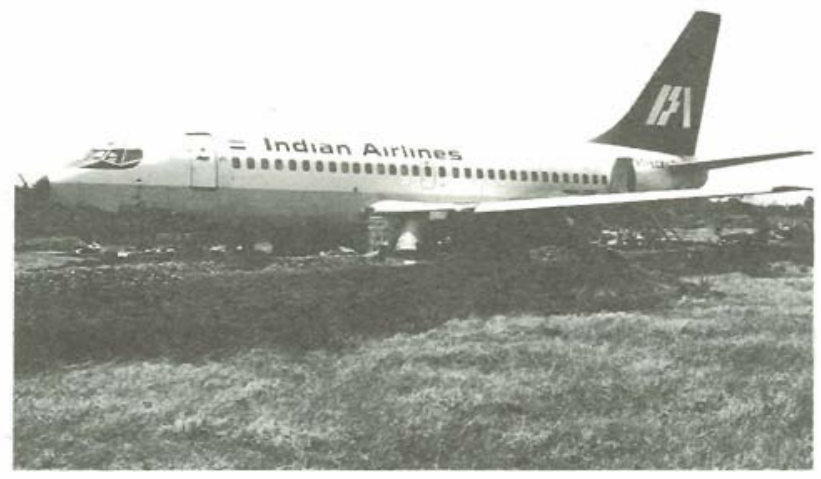

Fig. 1. Wreckage of the aircraft

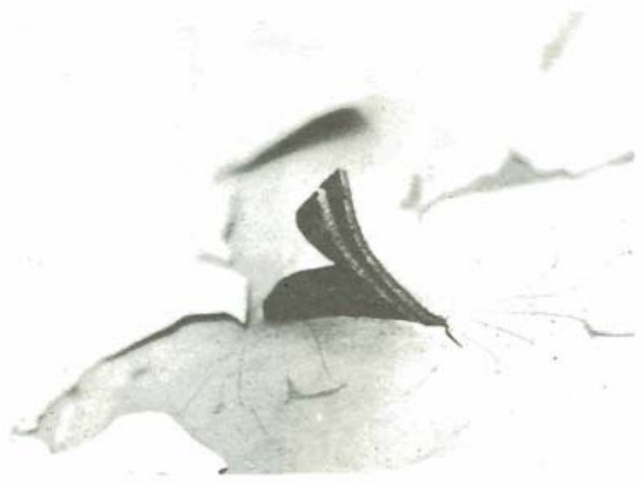

Fig. 2. Hole on the external skin of the toilet roof 

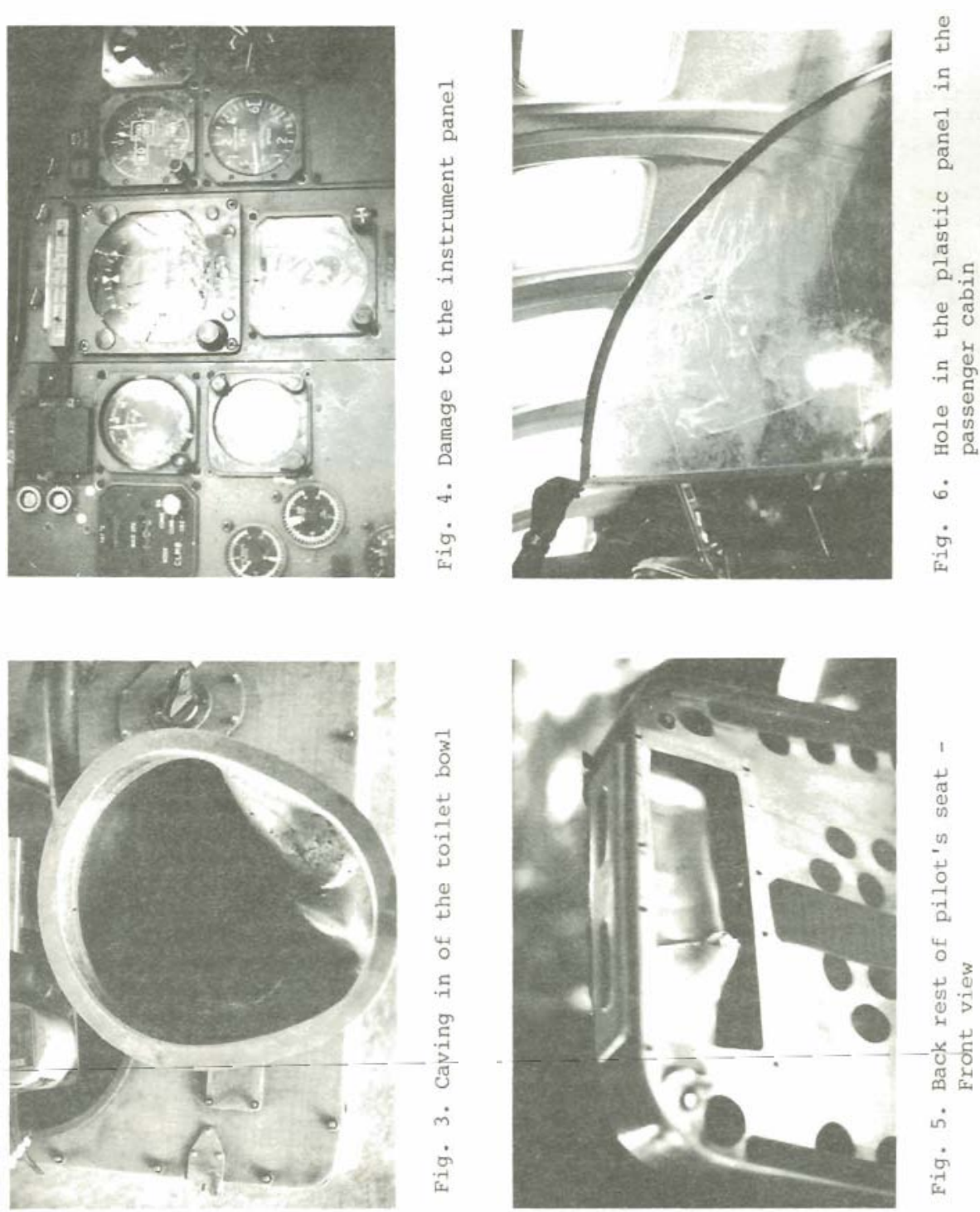
The small fragments were examined in a stereo binocular microscope and wherever necessary in a scanning electron microscope. The following unusual features were observed on the edges and the surfaces of some of the pieces.

Reverse slant. A number of sheet metal fragments of the waste towel showed a stepwise fracture edge, the slope of the slant fracture reversing alternately along the edge, Fig.7a.

Curls. Some of the fragments of the waste towel receptacle were found $\overline{c u r l e d}$ as shown in Fig.7b, with the free end rolled over itself one or two turns.

Curved fragments. Fragments were also found curved at the edges with a small radius of curvature, Fig. $7 \mathrm{c}$.

Dents. Several sharp and glancing dents were found in some of the pieces of the waste towel receptacle, Fig.7d.

Spall. In one of the fragments, metal was found spalled along the midthickness plane. Figure $7 e$ is a scanning electron fractograph of this feature.

Holes. In some of these fraqments, small holes were found pierced through the thickness. On larger holes, petaling and outward curling were noticed on the outer surface of the fragments, Fig.7f.

Spikes. Saw tooth like spikes were noticed in some of the pieces. One such piece shown in Fig.7g was identified as part of the aluminium backing under the stainless steel wash basin.

Craters. In a few pieces identified to be parts of the waste towel receptacle, a cluster of small craters was noticed with raised ridges along the periphery, as shown in fig. $7 \mathrm{~h}$.

Nondescript fragments. In addition, there were many tiny nondescript fragments of aluminium, of various shapes in the debris collected from the front area, Fig.7i.

\section{DISCUSSION}

The damage to the aircraft can be classified into two categories = (1) those that occurred in flight and (2) those caused-during and after landing. The aircraft overshot the runway hitting the approach lamps at the end of the runway and the poles of the inner fence and came to a halt on its belly near the outer fence. During these fast movements, considerable damage has been caused to the engines, undercarriage and underside. But the damages caused to the toilet area and the structure and fittings therein are of an entirely different nature and could not have been caused either by impact forces on landing or when the underside grazed the ground.

Features on sheet metals fractured by explosive forces are totally different in character from those caused by normal tensile and impact forces. When an explosion occurs, certain distinct signatures are left on the fraqments from the primary zone of explosion. These signatures survive the damage caused by subsequent ground impact and 

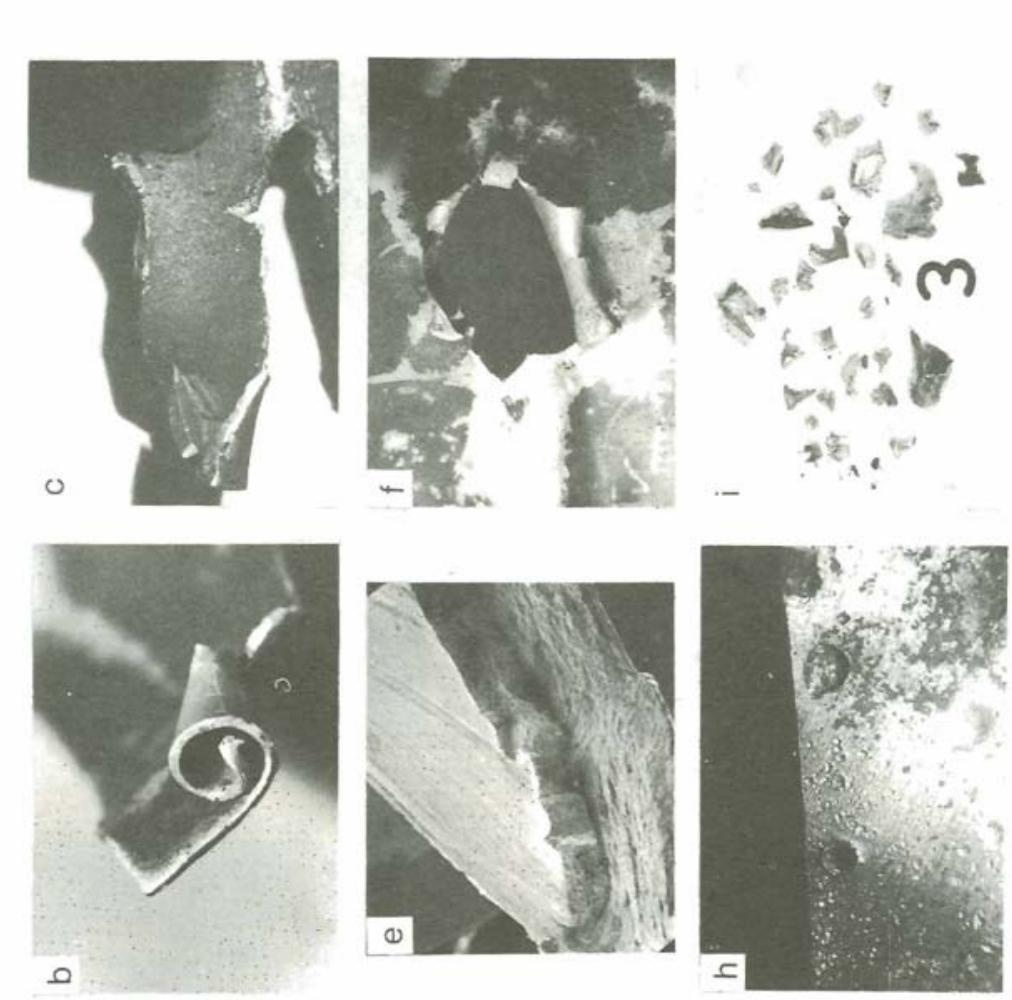

강

कै प

๑志

峞出

茫

ठ․

号

哥

出

r

$\$$.

낼

$-0$

บิ

I

苟 的

U

डी

可

का 0

o

4

$\$ \pi$

ఖ

() 궁
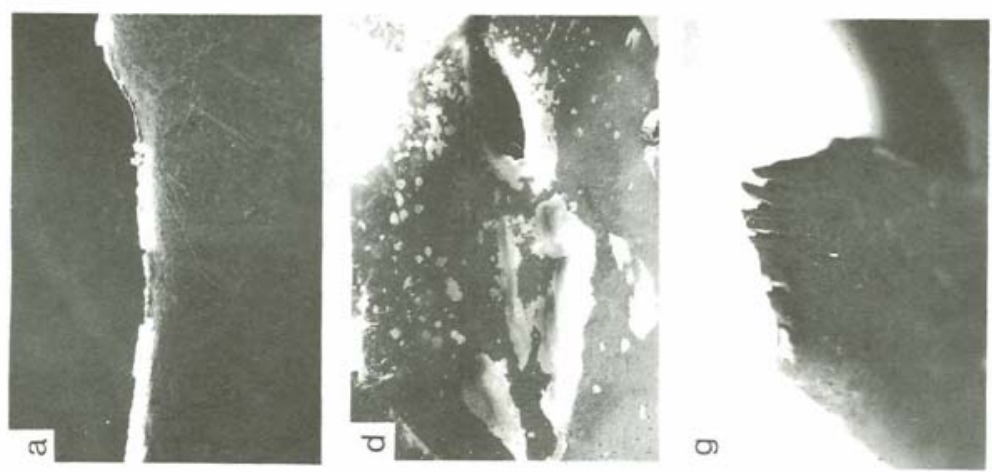

ㅇ

ธิ

की

-

ब.

प्山

n.

당

ذै

舟

든

$\therefore$

$\underset{-1}{\dot{\sigma}}$ 
have been well documented in literature. Tardif and Sterling (1967) have identified the signatures of explosive damage in aluminium, including the macroscopic features, morphology of the fragments and the surface damages due to explosion. Use of such information for detecting explosive sabotage of aircraft has been described by Newton (1968), Tardif and Sterling (1969) and Barer and Sterling (1970). In such cases, it is also possible to locate the centre of explosion by suitable trajectory tracing exercises (Barer and Sterling, 1970; Clancey, 1968).

The observed features described in the earlier section belong to this group of signatures produced on explosion. While some features like the reverse slant or some form of curled fragments may also be formed by other means, other features described above are produced only due to explosion. Craters with raised rims could not be caused by any other means during an aircraft crash and their presence is an almost certain proof of chemical explosion.

Explosion experiments were also carried out in the laboratory on aluminium sheet, with ammonium nitrate based explosives. The fragments thus produced also contained some of these characteristic signatures. This comparison also strongly indicated an in-flight explosion in the front toilet area of the aircraft.

The observed damages to the structure and fittings in and around, the toilet compartment further strengthens this view. A hole in the roof skin of the toilet, another in the pilot's seat back rest and a third in the plastic panel in the passenger cabin indicate that high velocity projectiles have travelled outwards in various directions from the toilet. The peeling off of the paint from the top skin of the fuselage between the cockpit and the front entrance, shown in Fig.1 could have happened only due to internal forces from underneath and not during or after landing. The orientation of the dent in the toilet bowl and the deformation of the wash basin indicate the centre of explosion to be under the wash basin. The larger pieces of the disintegrated aluminium waste paper receptacle have dents and holes indicating damage from inside to outside by an explosion. Further the innumerable craters which characterise the primary zone of chemical explosion were found in fragments from this container. All these evidences strongly point to this waste towel receptacle as the centre of explosion. This was also confirmed by the trajectory tracing method sketched in Fig.8. The residues collected from the inside surfaces of the fragments of the waste towel receptacle were got chemically analysed. The analysis indicated that. a mixture of ammonium nitrate and fuel oil had been used as the explosive.

\section{CONCLUSION}

Fractographic and surface examination of the debris collected from the aircraft conclusively established the primary cause of the accident to the aircraft to be a chemical explosion in the waste towel receptacle placed below the wash basin in the front toilet. Because of this explosion, a number of instruments were not available to the pilot and he was forced to make an emergency landing. The aircraft landed with high ground velocity and overshot the runway causing subsequent damages to the undercarriage and underside. 
The authors are thankful to Dr S.R.Valluri, Director and Dr A.K.Singh, Head, Materials Science Division, National Aeronautical Laboratory, for their critical comments and encouragement during this investigation. They also thank the Director General of Civil Aviation, Government of India, for permission to present this work in ICF 6.

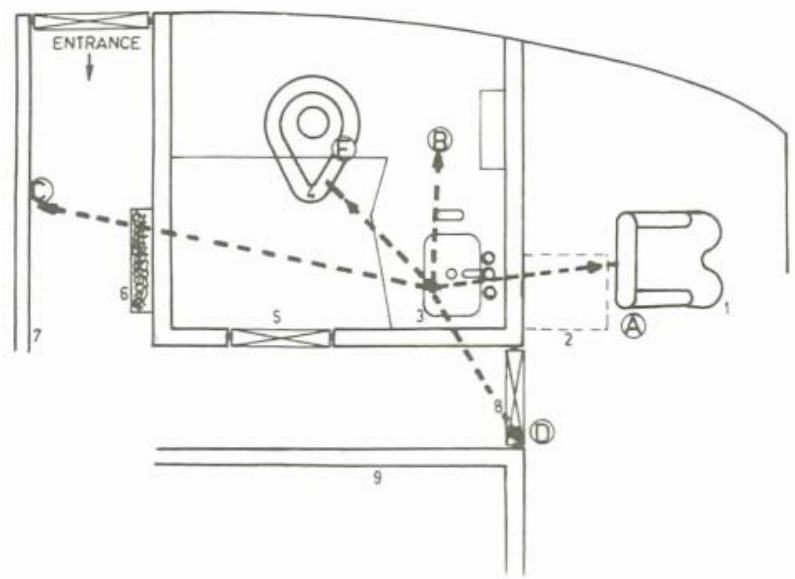
1. Pilots's seat
2. Observer's seat
3. Wash basin
4. Toilet bowl
5. Toilet door
6. Cabin crew seat
7. Plastic panel
8. Cockpit door
9. Pantry
A. Holes in the backrest of pilots's seat
B. Hole in the external skin
c. Hole in the plastic panel
D. Holes in the panel
E. Dent in the panel bowl

Fig.8. Trajectories of projectiles from the centre of explosion REFERENCES

Barer, R. D., and T. S. Sterling (1970). Metal Proqress, 98 No.5, 84-86.

Clancy, V. J. (1968). Canadian Aeronautics and Space J., 14, 337-343. Newton, E. (1968). Canadian Aeronautics and Space J., 14, 385-395. Tardif, H. P., and T. S. Sterling (1967). J. Forensic Sciences, 12 No.3, 247-272.

Tardif, H. P., and T. S. Sterling (1969). Canadian Aeronautics and Space J., 15, 19-27. 